Supporting Information

\title{
Ultrahigh Ion-Selective and Durable Nafion-NdZr Composite Layer Membranes for All-Vanadium Redox Flow Batteries
}

\author{
Syed Imdadul Hossain, Md. Abdul Aziz, Sangaraju Shanmugam* \\ Department of Energy Science \& Engineering, Daegu Gyeongbuk Institute of Science \& \\ Technology (DGIST), 333, Techno jungang-daero, Hyeonpung-myeon, Dalseong-Gun, Daegu, \\ Republic of Korea, 42988 \\ *E-mail: sangarajus@dgist.ac.kr
}

Number of pages: 19 (S1-S19)

Number of tables: 02 (Table S1 and Table S2)

Number of figures: 12 (Figure S1-Figure S12) 


\section{EXPERIMENTAL DETAILS}

Measurement Method of $\mathrm{VO}^{2+}$ Permeability and Ion Selectivity. Vanadium ion crossover in membranes were measured by a membrane diffusion cell. The membrane with a specific area of 9 $\mathrm{cm}^{2}$ was clamped between two compartments. $150 \mathrm{~mL}$ of $1.5 \mathrm{~mol} \mathrm{~L}^{-1} \mathrm{VOSO}_{4}$ in $3 \mathrm{~mol} \mathrm{~L}^{-1} \mathrm{H}_{2} \mathrm{SO}_{4}$ and $150 \mathrm{~mL}$ of $1.5 \mathrm{~mol} \mathrm{~L}^{-1} \mathrm{MgSO}_{4}$ in $3 \mathrm{~mol} \mathrm{~L}^{-1} \mathrm{H}_{2} \mathrm{SO}_{4}$ solution, were loaded in left and right compartment, respectively to either minimize the effects of osmotic pressure or neutralize the ionic strengths. The solution in both tanks were stirred by magnetic stirrers during the entire measurement at ambient temperature to avoid concentration polarization. Following that, the aliquot sample was collected from the right tank, at specific time intervals, and the concentration of $\mathrm{VO}^{2+}$ was determined by an ultraviolet-visible (UV-vis) spectrometer. The crossover rate of vanadium ion was determined using the equation in reference [S1]. Moreover, the membrane ion selectivity was measured from the proton conductivity $(\delta)$ and vanadium ion permeability [S1].

Material Characterization. Structure of $\mathrm{Nd}_{2} \mathrm{Zr}_{2} \mathrm{O}_{7}$ fillers and surface morphology were investigated by field emission scanning electron microscope (FESEM, Hitachi, S-4800II) with 3 $\mathrm{kV}$ setup. The membrane was coated with osmium for FESEM investigation. To determine the microstructures and lattice fringe of $\mathrm{Nd}_{2} \mathrm{Zr}_{2} \mathrm{O}_{7}$, field emission transmission electron microscope (FETEM, Hitachi, HF-3300) was used with an acceleration voltage of $300 \mathrm{kV}$. The $\mathrm{Nd}_{2} \mathrm{Zr}_{2} \mathrm{O}_{7}$ powder was dispersed in ethanol, and the dispersion was dropped on a copper grid using a micropipette to carry out FETEM analysis.The crystal structure of samples was analyzed by powder X-ray diffraction (XRD, Panalytical, Empyrean), CuKa radiation with setting up $40 \mathrm{kV}$ and $30 \mathrm{~mA}$. The surface morphology of different membranes were analyzed by atomic force microscopy (AFM, psia NX-10) with $20 \mathrm{~nm}$ of tip radius and $40 \mathrm{~N} \mathrm{~m}^{-1}$ of spring constant. The operation of FT-IR was carried out in Agilent Cary 600 FT-IR spectroscopy equipped with an auto-sampler (over 3200 scans) in the range from 4000 to $500 \mathrm{~cm}^{-1}$ using a resolution of $4 \mathrm{~cm}^{-1}$.

The EDS analysis of Nafion-NdZr (1\%) and Nafion-NdZr (1\%)/[P-S $]_{2}$ membranes were investigated using Ultra-High Resolution FE-SEM (SU8230). N 1s and C 1s signal of Nafion$\mathrm{NdZr}(1 \%) /[\mathrm{P}-\mathrm{S}]_{2}$ composite layer membrane, XPS survey scan of Nafion-NdZr (1\%) and Nafion-NdZr $(1 \%) /[\mathrm{P}-\mathrm{S}]_{2}$ membranes were investigated by the X-ray photoelectron spectroscopy (Thermo Scientific ESCALAB 250Xi).

Thermogravimetric analysis (Thermo plus EVO, TG8120) was investigated to evaluate the thermal stability of the membranes. The sample was kept in a crucible then it was heated from ambient 
temperature to $600^{\circ} \mathrm{C}$ at a heating rate of $10^{\circ} \mathrm{C} \mathrm{min}^{-1}$ under an oxygen atmosphere. The mechanical stability of the membranes was observed by the tensile test machine (SFM-100kN, united testing system, Inc. the USA) at room temperature with a crosshead speed of $5 \mathrm{~mm} \mathrm{~min}^{-1}$. The size of each membrane sample in the dry state was $36 \times 18 \mathrm{~mm}^{2}$.

Water uptake and swelling degree were investigated by measuring the weight of membranes and the change in the membrane length, respectively in dry and wet conditions. The water uptake and swelling ratio were acquired according to the following equations [S1].

$$
\begin{aligned}
& \text { Water uptake }(\%)=\frac{\mathrm{W}_{\text {wet }}-\mathrm{W}_{\text {dry }}}{\mathrm{W}_{\text {dry }}} \times 100 \\
& \text { Swelling degree }(\%)=\frac{\mathrm{L}_{\mathrm{wet}}-\mathrm{L}_{\text {dry }}}{\mathrm{L}_{\mathrm{dry}}} \times 100
\end{aligned}
$$

Where, $\mathrm{W}_{\text {wet }}$ is the wet membrane and $\mathrm{W}_{\text {dry }}$ is the dry membrane weight. Similarly, $\mathrm{L}_{\text {wet }}$ is the wet membrane and $\mathrm{L}_{\mathrm{dry}}$ is the dry membrane length.

The ion exchange capacity (IEC, $\mathrm{mmol} \mathrm{g}^{-1}$ ) of the membranes was checked by acid-base titration by using phenolphthalein as an indicator. In this method, the sample was soaked in $50 \mathrm{~mL}$ of a $3 \mathrm{M} \mathrm{NaCl}$ aqueous solution for $24 \mathrm{~h}$ to exchange $\mathrm{H}^{+}$ions with $\mathrm{Na}^{+}$ions. After that, the solution was titrated using $0.01 \mathrm{M} \mathrm{NaOH}$ solution. The IEC was calculated based on the equation (3) [S1].

$$
\mathrm{IEC}=\frac{\mathrm{V}_{\mathrm{NaOH}} \times \mathrm{C}_{\mathrm{NaOH}}}{\mathrm{W}_{\mathrm{dry}}}
$$

Where, $\mathrm{V}_{\mathrm{NaOH}}$ is the volume of $\mathrm{NaOH}$ used at the neutralized point, $\mathrm{C}_{\mathrm{NaOH}}$ is the concentration of $\mathrm{NaOH}$ and Wdry was the dry membrane weight.

The proton conductivity of the samples was obtained by fixing it in between two platinum electrodes of a membrane conductivity cell (Bekktech), at $100 \%$ relative humidity (RH); $25^{\circ} \mathrm{C}$ temperature; by operating conductivity cell (Bekktech), hydrogen gas was being passed during measurement. The conductivity of the membranes were determined according to the reference [S1].

The Measurement of Vanadium Flow Battery Performance. The battery was assembled by sandwiching the membrane with the geometric area of $9 \mathrm{~cm}^{2}$ between two carbon felt electrodes, and no electro-catalyst was used, in turn assembled between two graphite plates act as current collectors. Two copper sheets were attached with two graphite plates. Following that, the cell 
assemblage was fastened by two polyvinyl chlorides (PVC) end plates. Eventually, the carbon electrode ( $5 \mathrm{~mm}$ uncompressed thickness) was activated by being thermally treatment at $500^{\circ} \mathrm{C}$ for $30 \mathrm{~min}$ with $5^{\circ} \mathrm{C} / \mathrm{min}$ heating rate. At $40 \mathrm{~mA} \mathrm{~cm}{ }^{-2}$ current density in ambient temperature, the cyclic charge-discharge curves of the battery was constructed with the Recast Nafion, Recast Nafion-[P-S] layer membrane, Nafion-NdZr composite membrane, and Nafion-NdZr-[P-S] composite layer thin membrane.

A $50 \mathrm{~mL}$ of vanadium electrolyte with a composition of $1.7 \mathrm{M} \mathrm{V}( \pm 3 \%), \mathrm{V}^{3+} / \mathrm{V}^{4+} 1: 1( \pm 3 \%)$, $4.5 \mathrm{M} \mathrm{SO}_{4}{ }^{-}( \pm 5 \%)$ was applied in each tank. The electrolyte flow rate of $15 \mathrm{~mL} \mathrm{~min}^{-1}$ was maintained by a peristaltic pump (Reglo ICC $2 \mathrm{ch}$ Pump). Anolyte and catholyte tanks were deaerated by continual nitrogen flow to abstain oxidation of vanadium solution.

A charge-discharge voltage of 1.6 to $1 \mathrm{~V}$ was applied to minimize the corrosion between electrodes and graphite plates. The self-discharge rate of the battery was evaluated at ambient temperature by time tracking the open circuit voltage (OCV), which dropped below $0.8 \mathrm{~V}$. The cyclic efficiencies of the VFB were ascertained at different current densities using the equation in reference [S1].

The Measurement of Oxidative and Chemical Stability. The oxidative stability of membranes was observed by immersion of a small part of the membrane in Fenton's reagent ( $2 \mathrm{ppm} \mathrm{FeSO}_{4}$ in $3 \% \mathrm{H}_{2} \mathrm{O}_{2}$ ) at $80^{\circ} \mathrm{C}$ and calculated the residual weight of the sample after $1 \mathrm{~h}$. In the meantime, the membranes were observed every 15 min to record any changes in appearance until they began to disintegrate. On the other hand, the chemical stability of the membranes was investigated by immersion in $1.5 \mathrm{M} \mathrm{VO}^{2+}$ in $3.0 \mathrm{M} \mathrm{H}_{2} \mathrm{SO}_{4}$ solution up to 4 weeks. The weight losses of membranes were investigated using the equation in reference [S2]. 

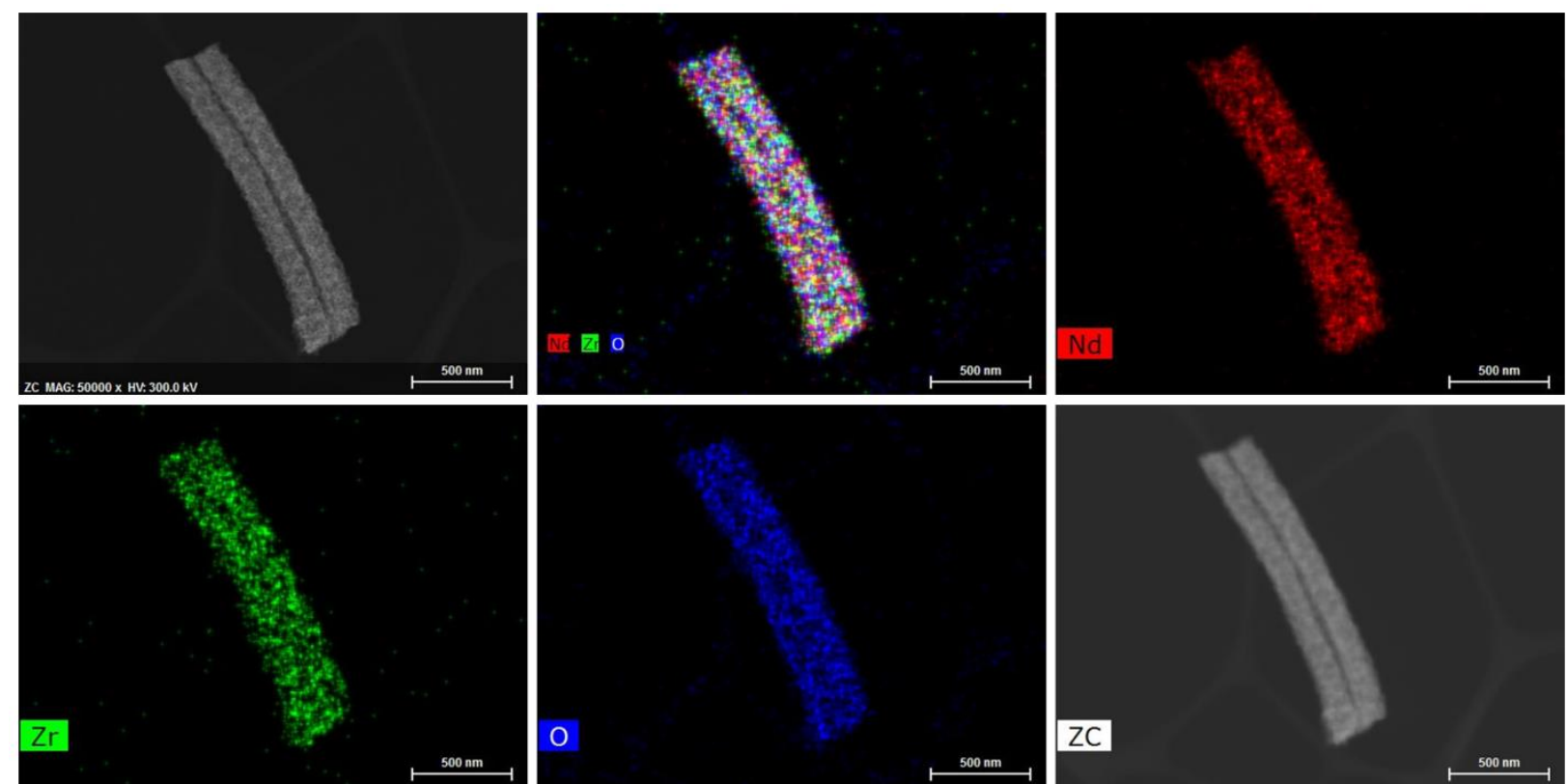

Figure S1. FETEM elemental mapping analysis of $\mathrm{Nd}_{2} \mathrm{Zr}_{2} \mathrm{O}_{7} \mathrm{NT}$. 


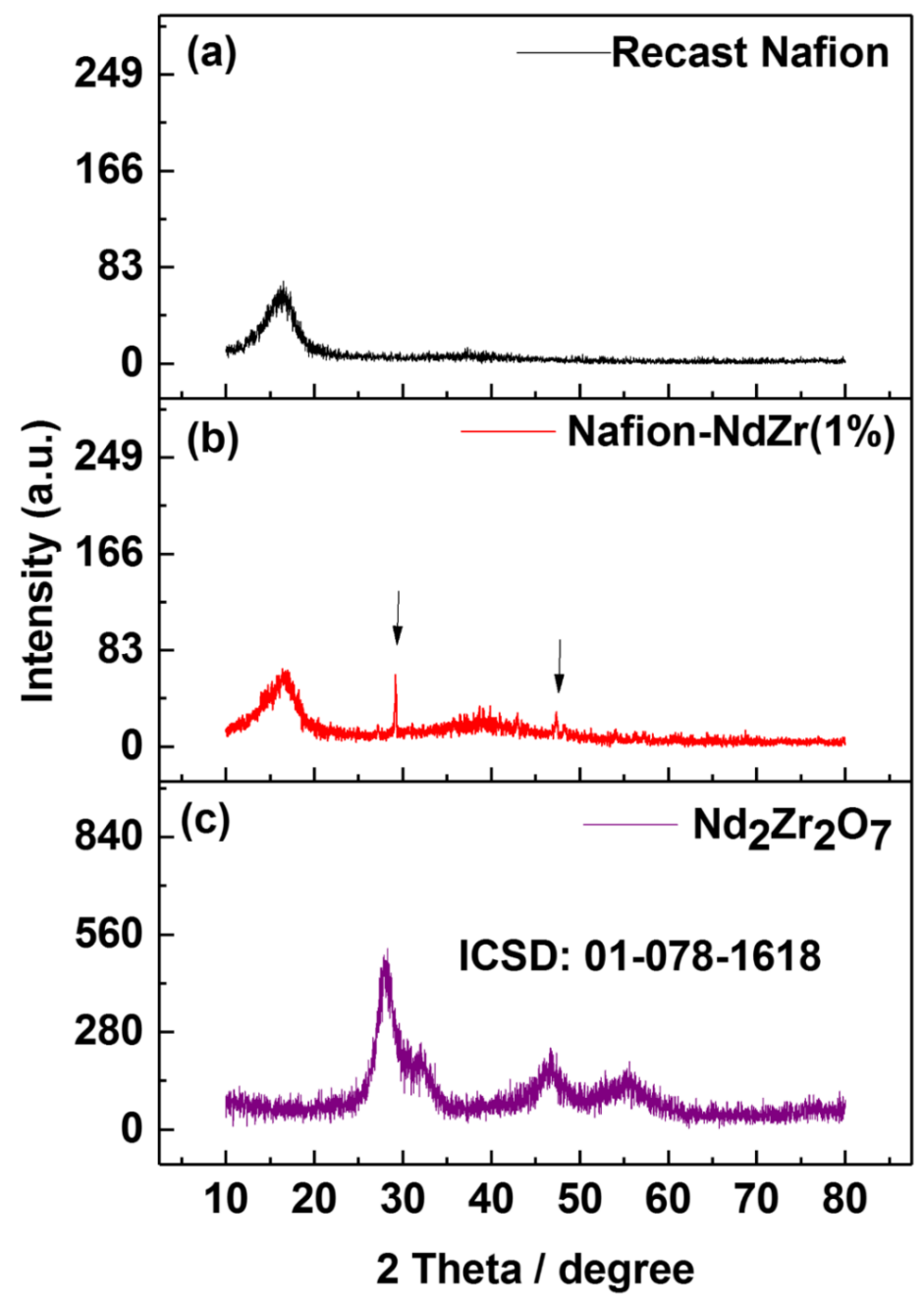

Figure S2. XRD pattern of (a) recast Nafion, (b) Nafion-NdZr (1\%), and (c) $\mathrm{Nd}_{2} \mathrm{Zr}_{2} \mathrm{O}_{7} \mathrm{NT}_{\text {. }}$. 


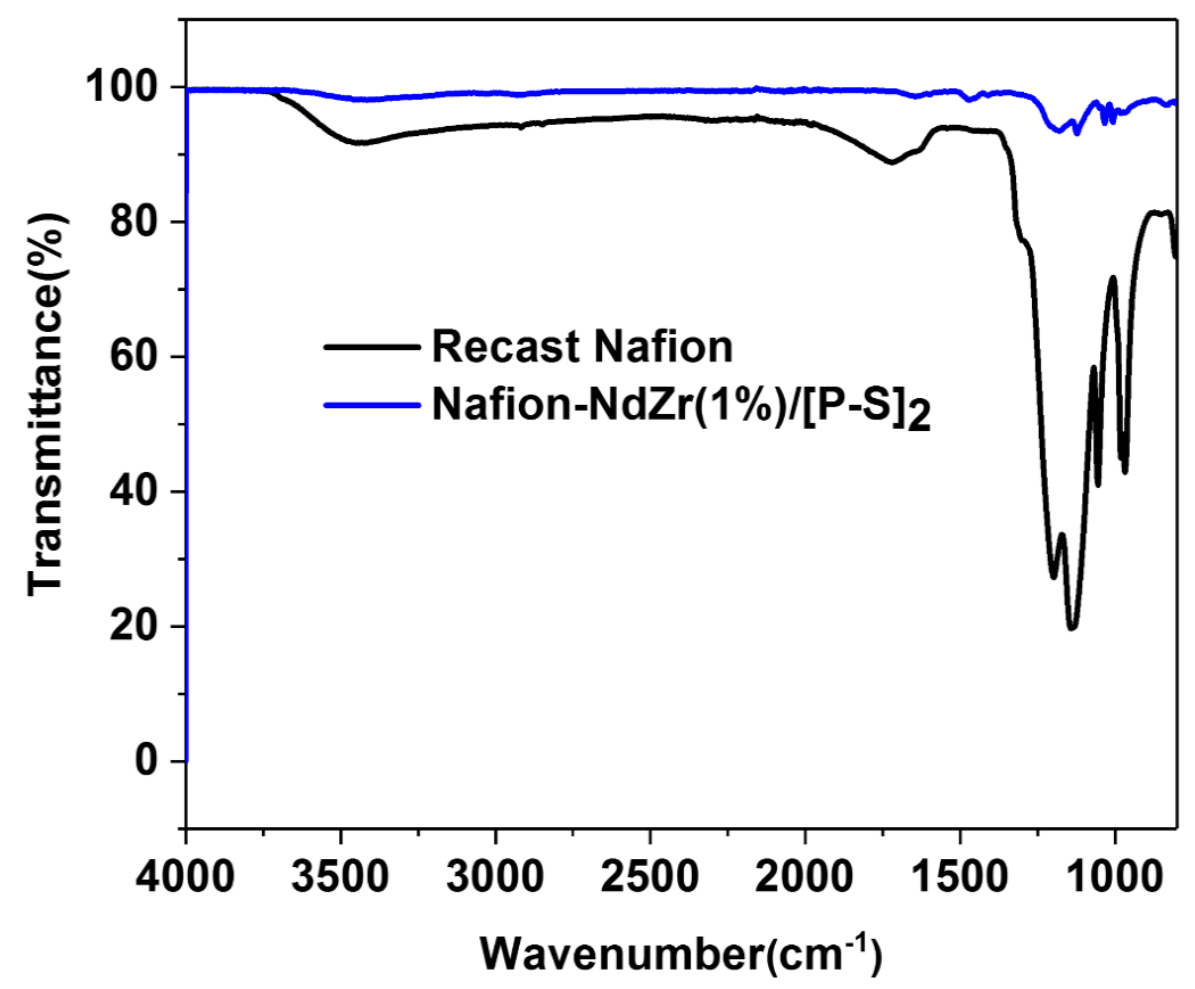

Figure S3. FTIR of recast Nafion and Nafion-NdZr (1\%)/[P-S $]_{2}$ membranes. 
(a)
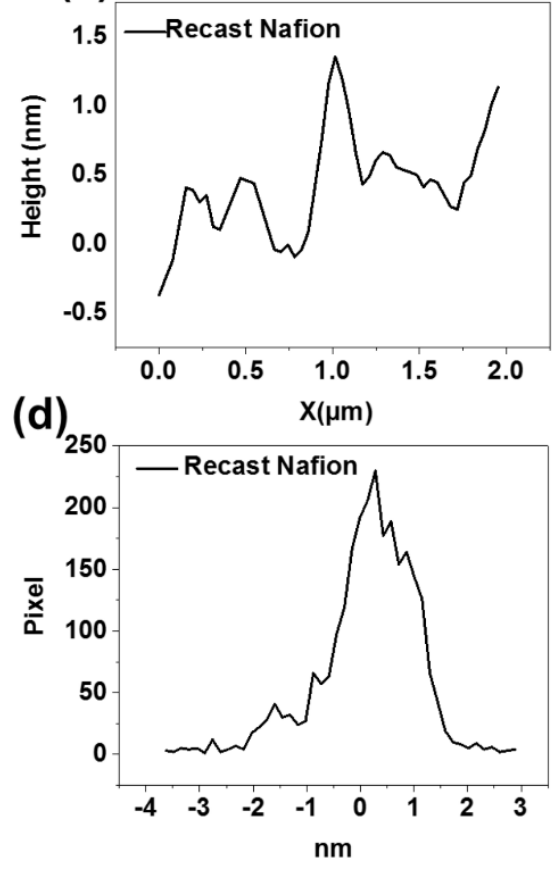

(b)

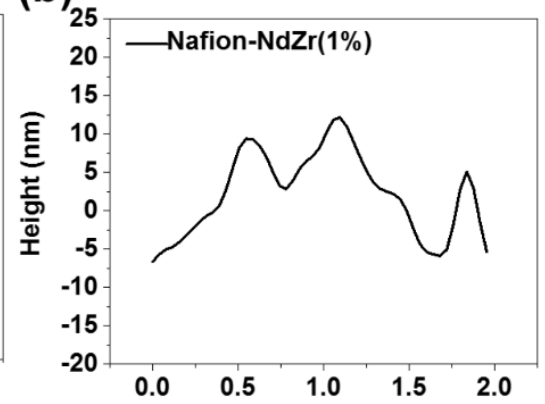

(e)

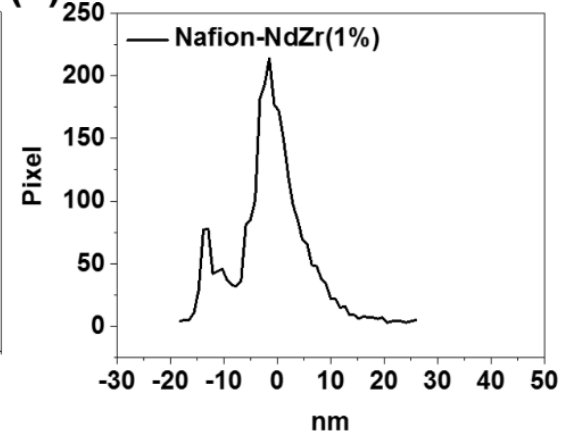

(c)

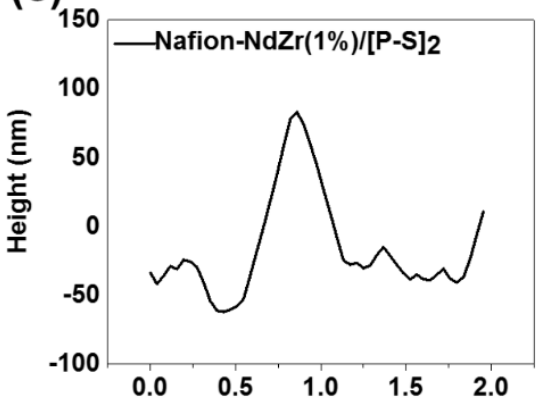

(f)

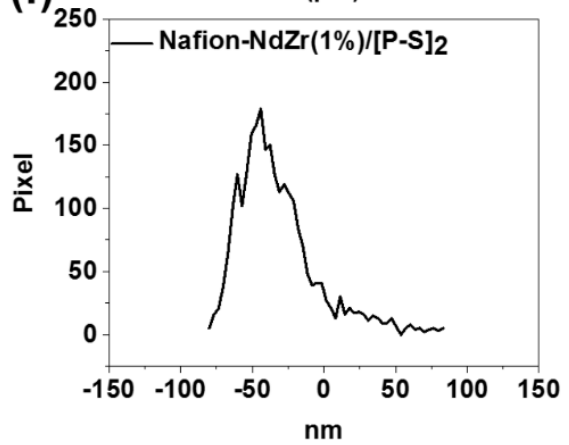

Figure S4. Line profile and histogram of recast Nafion (a) and (d), Nafion $\operatorname{NdZr}(1 \%)$ (b) and (e), Nafion- $\mathrm{NdZr}(1 \%) /[\mathrm{P}-\mathrm{S}]_{2}$ (c) and (f). 

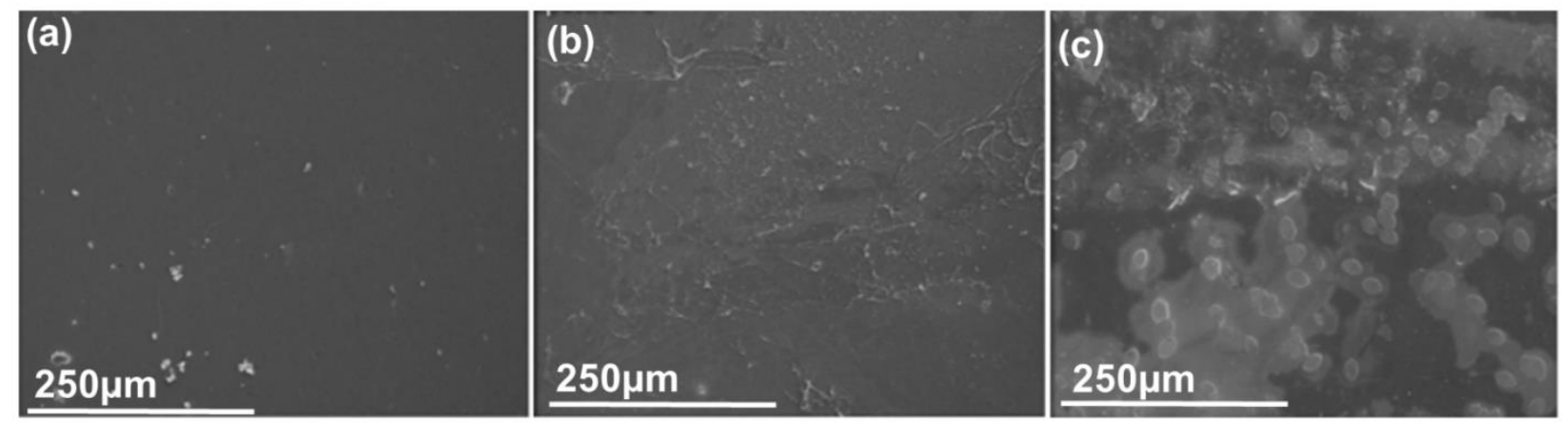

Figure S5. FESEM EDS images of (a) Nafion-NdZr(1\%) composite membrane. (b) Nafion$\mathrm{NdZr}(1 \%) /[\mathrm{P}-\mathrm{S}]_{2}$ composite layer membrane. (c) Nafion-NdZr(1\%)/[P-S $]_{2}$ composite layer membrane after 200 cycles charge-discharge in VFB.

Table S1 EDS element analysis of the surface of Nafion-NdZr (1\%), Nafion-NdZr (1\%)/[P-S $]_{2}$ before and after VFB operation.

\begin{tabular}{cccc}
\hline Elements (at $)$ & Nafion-NdZr(1\%) & $\begin{array}{l}\text { Nafion-NdZr(1\%)/[P- } \\
\text { S }]_{2}(\text { Before VFB) }\end{array}$ & $\begin{array}{c}\text { Nafion-NdZr(1\%)/[P-S }]_{2} \\
\text { (After VFB) }\end{array}$ \\
\hline $\mathrm{C}$ & 32.00 & 37.12 & 19.52 \\
$\mathrm{~N}$ & $\mathrm{~N} / \mathrm{A}$ & 0.98 & 0.89 \\
$\mathrm{O}$ & 8.52 & 7.73 & 49.73 \\
$\mathrm{~F}$ & 57.58 & 51.34 & 13.31 \\
$\mathrm{Na}$ & $\mathrm{N} / \mathrm{A}$ & 0.77 & 0.03 \\
$\mathrm{~S}$ & 1.65 & 1.86 & 11.24 \\
$\mathrm{~V}$ & $\mathrm{~N} / \mathrm{A}$ & $\mathrm{N} / \mathrm{A}$ & 5.02 \\
$\mathrm{Zr}$ & 0.14 & 0.12 & 0.15 \\
$\mathrm{Nd}$ & 0.11 & 0.10 & 0.11 \\
\hline
\end{tabular}




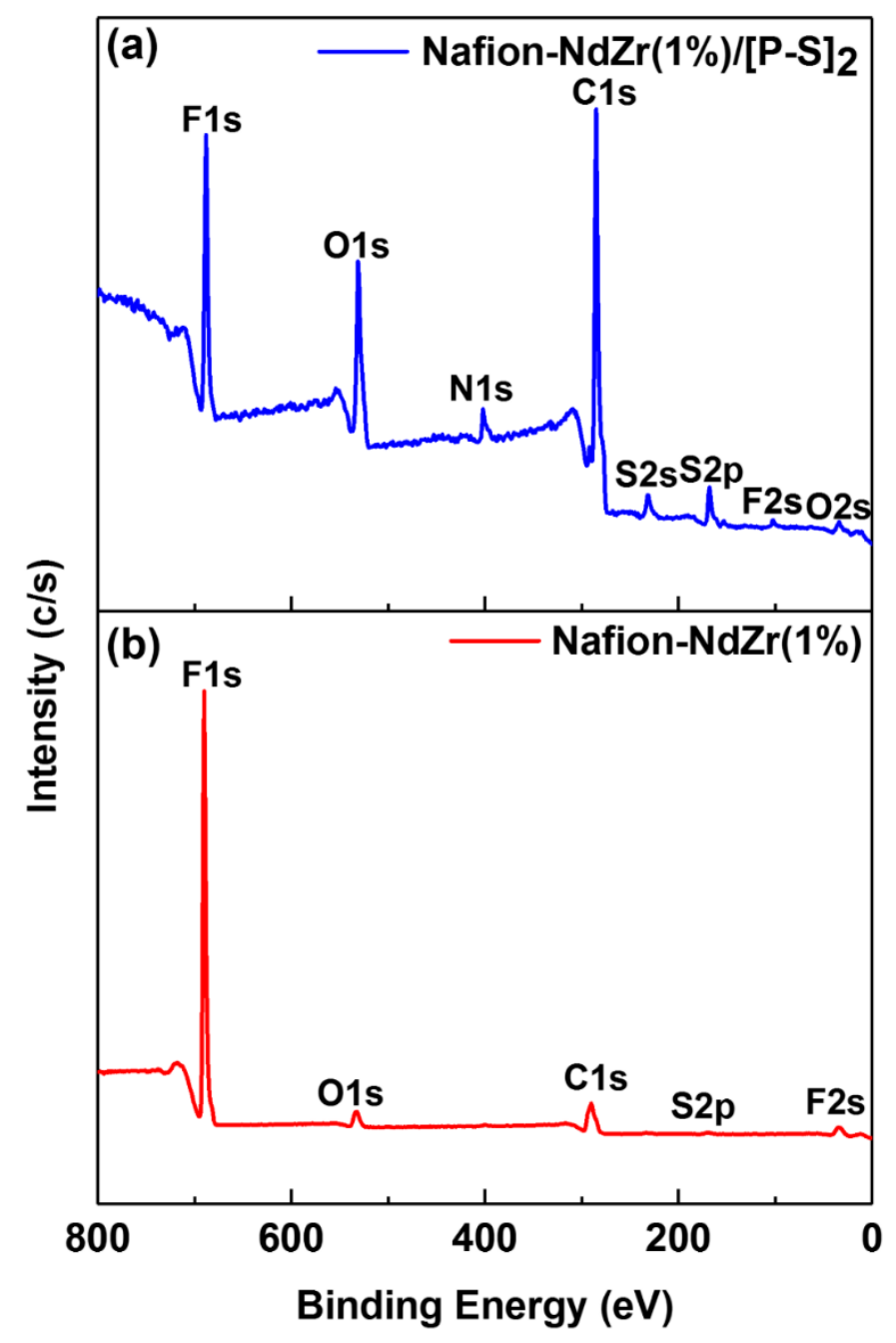

Figure S6. The XPS survey scan of (a) Nafion-NdZr (1\%)/[P-S $]_{2}$ and (b) Nafion-NdZr (1\%) membranes. 


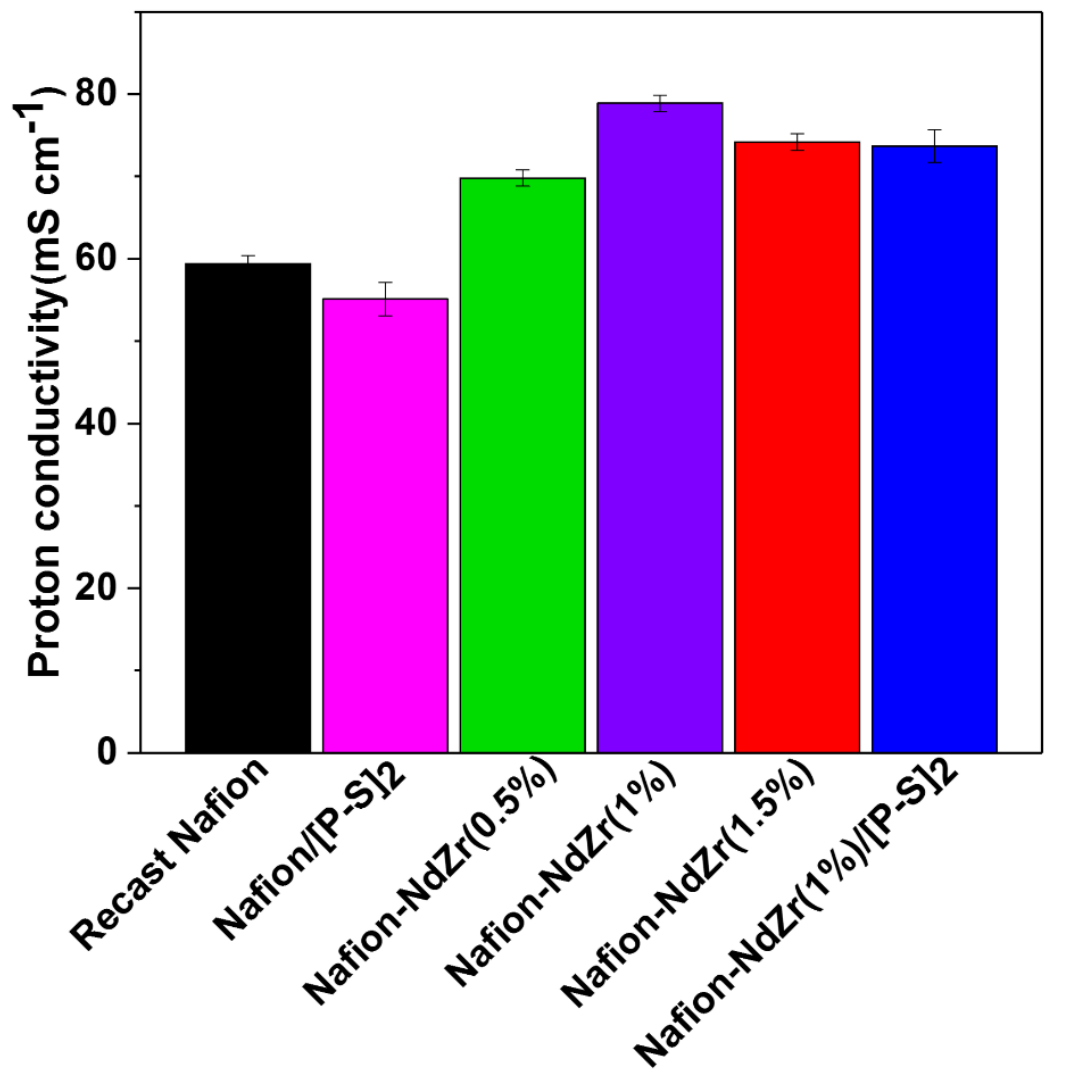

Figure S7. Proton conductivity of recast Nafion, recast Nafion/[P-S $]_{2}, \mathrm{Nafion}-\mathrm{NdZr}(0.5 \%)$, Nafion-NdZr (1\%), Nafion-NdZr (1.5\%), and Nafion-NdZr (1\%)/[P-S $]_{2}$ membranes. 


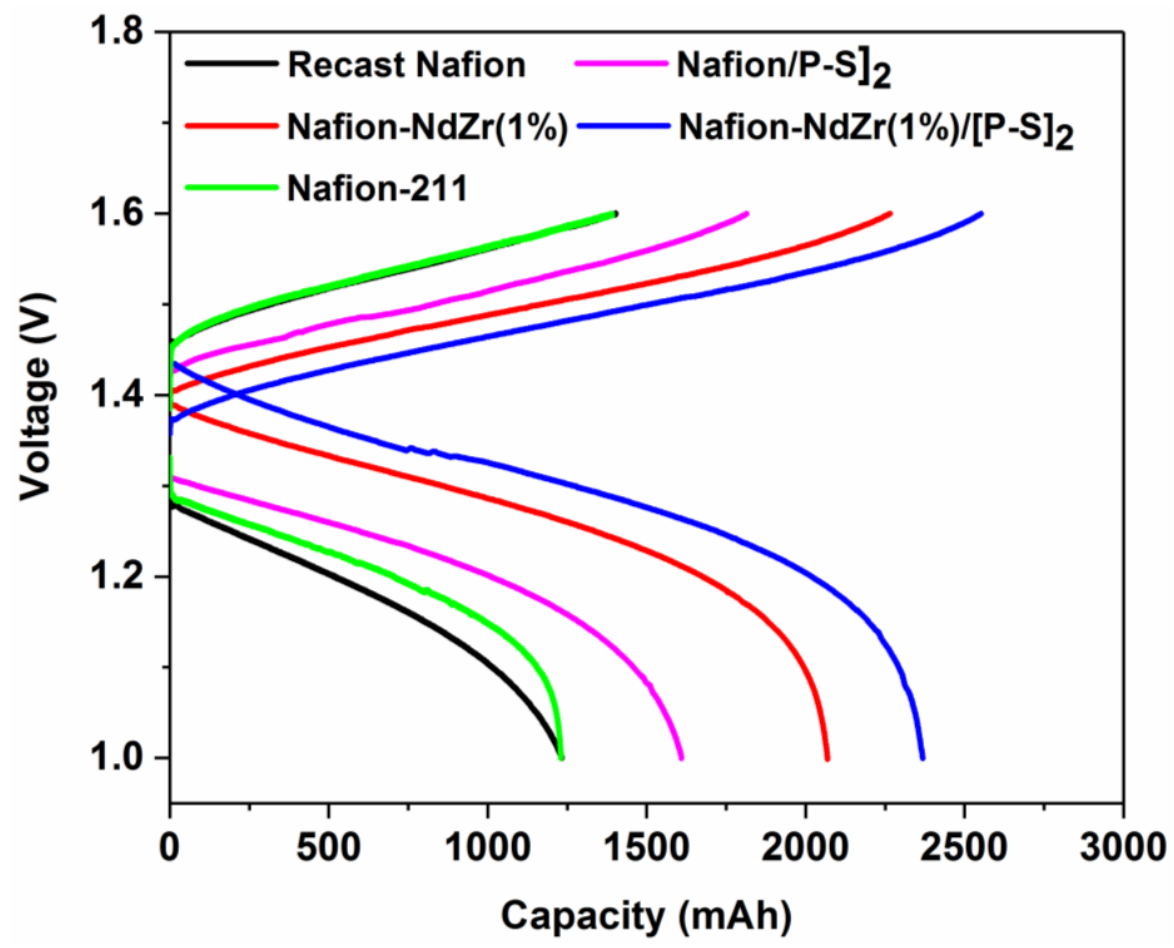

Figure S8. VFB charge-discharge capacity curves of different membranes at current density of $40 \mathrm{~mA} \mathrm{~cm}^{-2}$. 


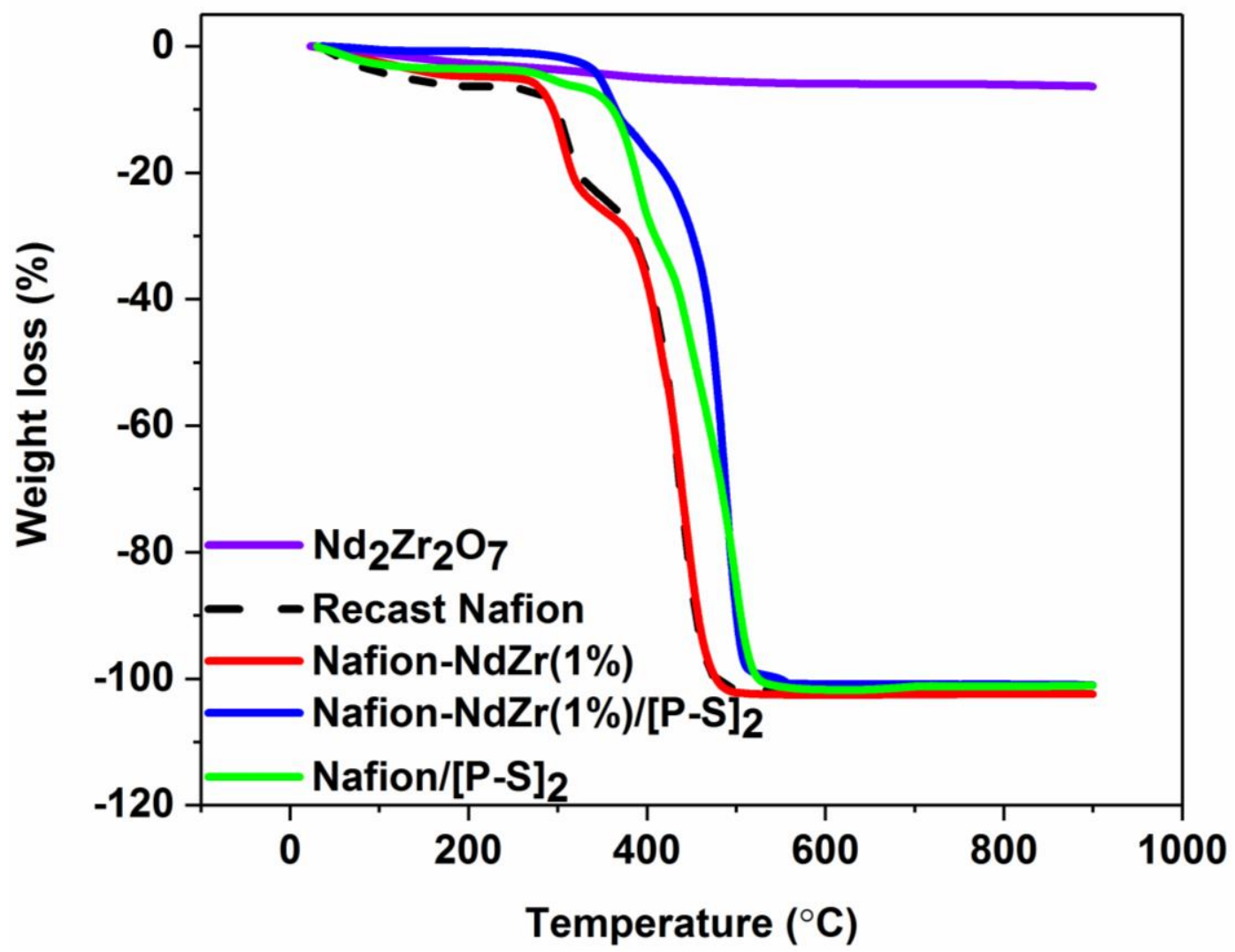

Figure S9. TGA analysis of $\mathrm{Nd}_{2} \mathrm{Zr}_{2} \mathrm{O}_{7} \mathrm{NT}$, recast Nafion, Nafion-NdZr (1\%), Nafion$\mathrm{NdZr}(1 \%) /[\mathrm{P}-\mathrm{S}]_{2}$, and Nafion/[P-S $]_{2}$ membranes measured at room temperature to $600{ }^{\circ} \mathrm{C}$ with a heating rate of $10^{\circ} \mathrm{C} \mathrm{min}^{-1}$ in an air atmosphere. 


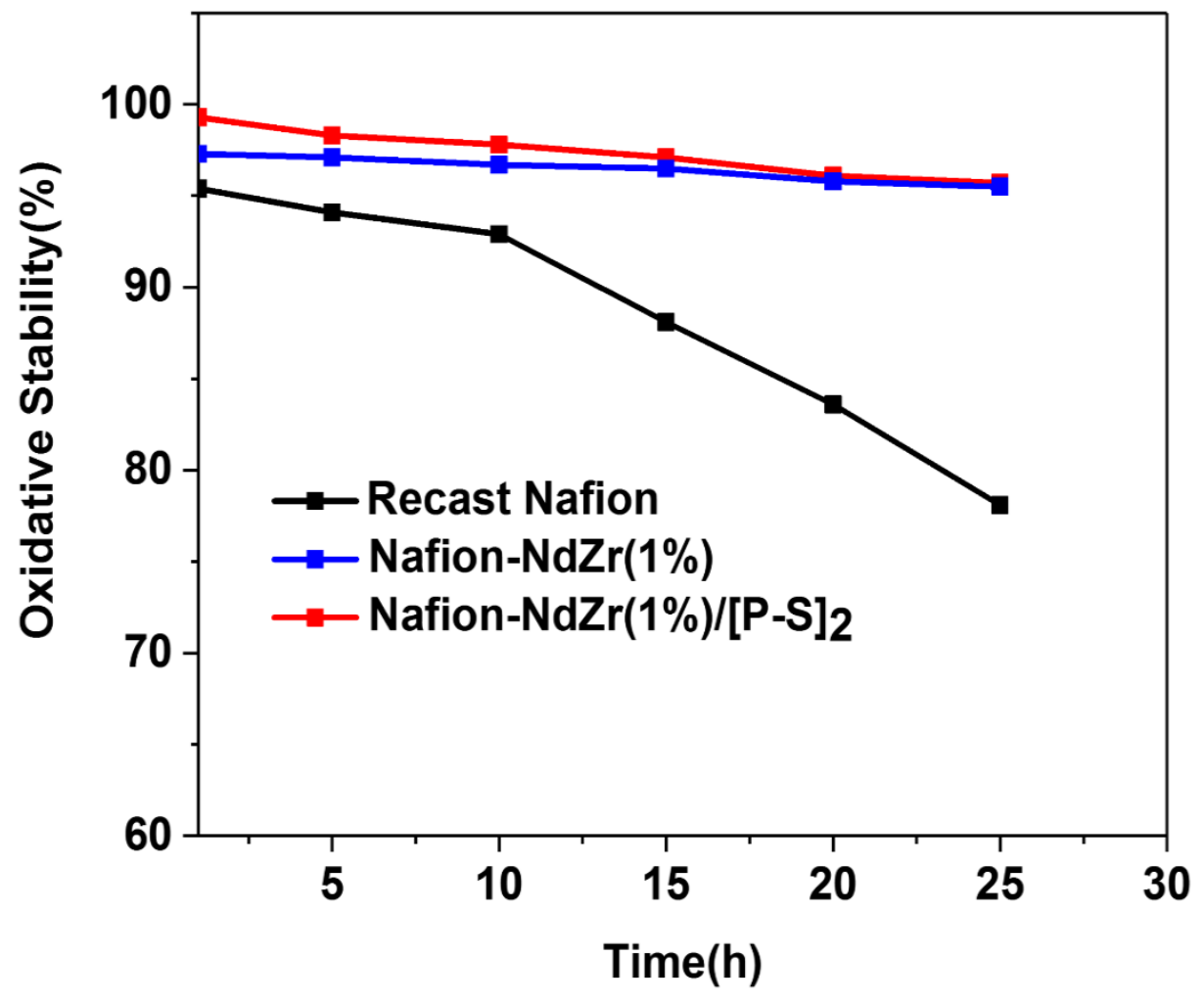

Figure S10. Oxidative stability test of recast Nafion, Nafion-NdZr (1\%), and Nafion-NdZr $(1 \%) /[\mathrm{P}-\mathrm{S}]_{2}$ membranes. 

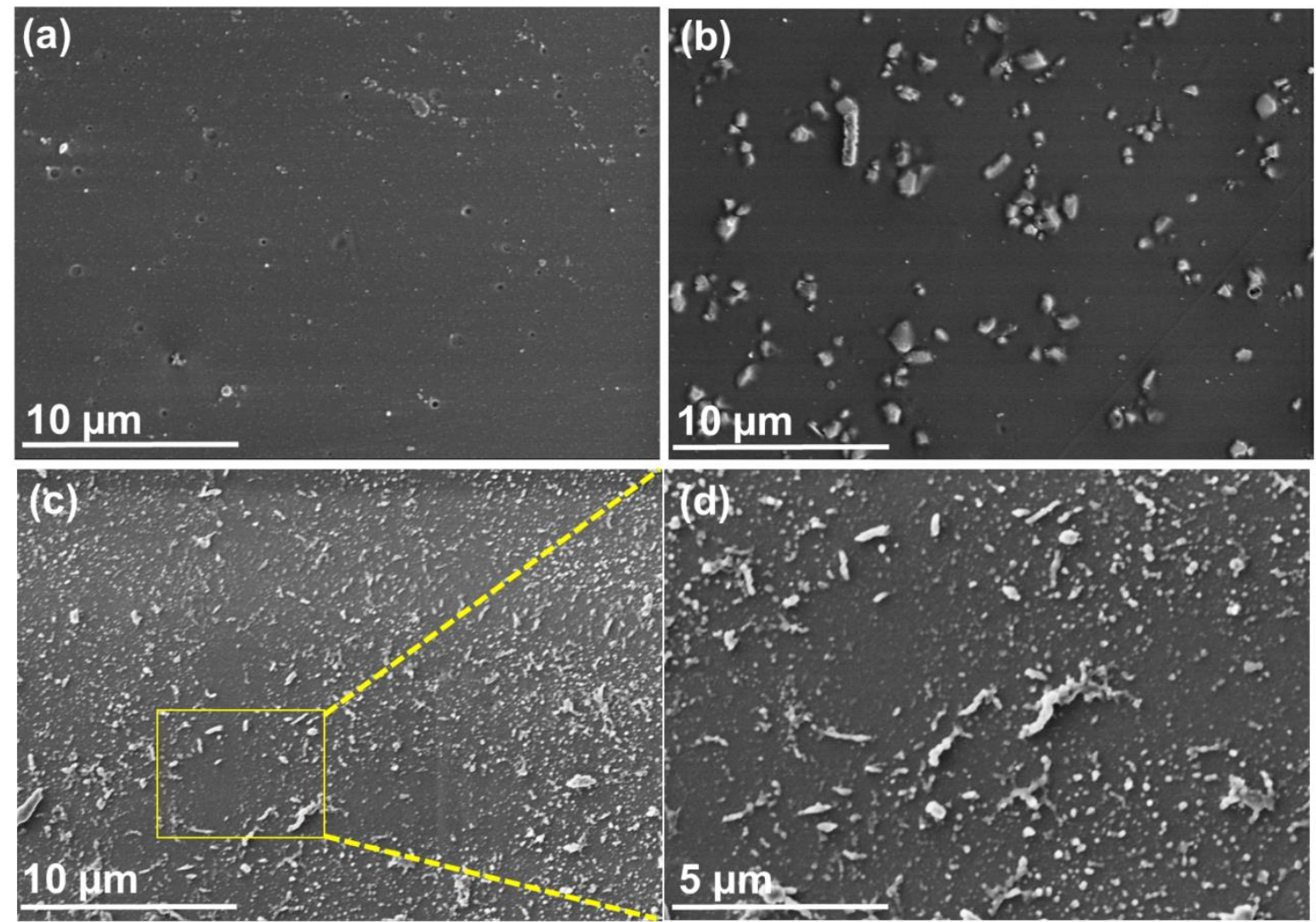

Figure S11. FESEM analysis of (a) recast Nafion after 100 cycles charge-discharge in VFB (b) Nafion-NdZr (1\%) composite membrane after 200 cycles charge-discharge in VFB. (c-d) Nafion-NdZr (1\%)/[P-S $]_{2}$ composite layer membrane after 200 cycles charge-discharge in VFB. 

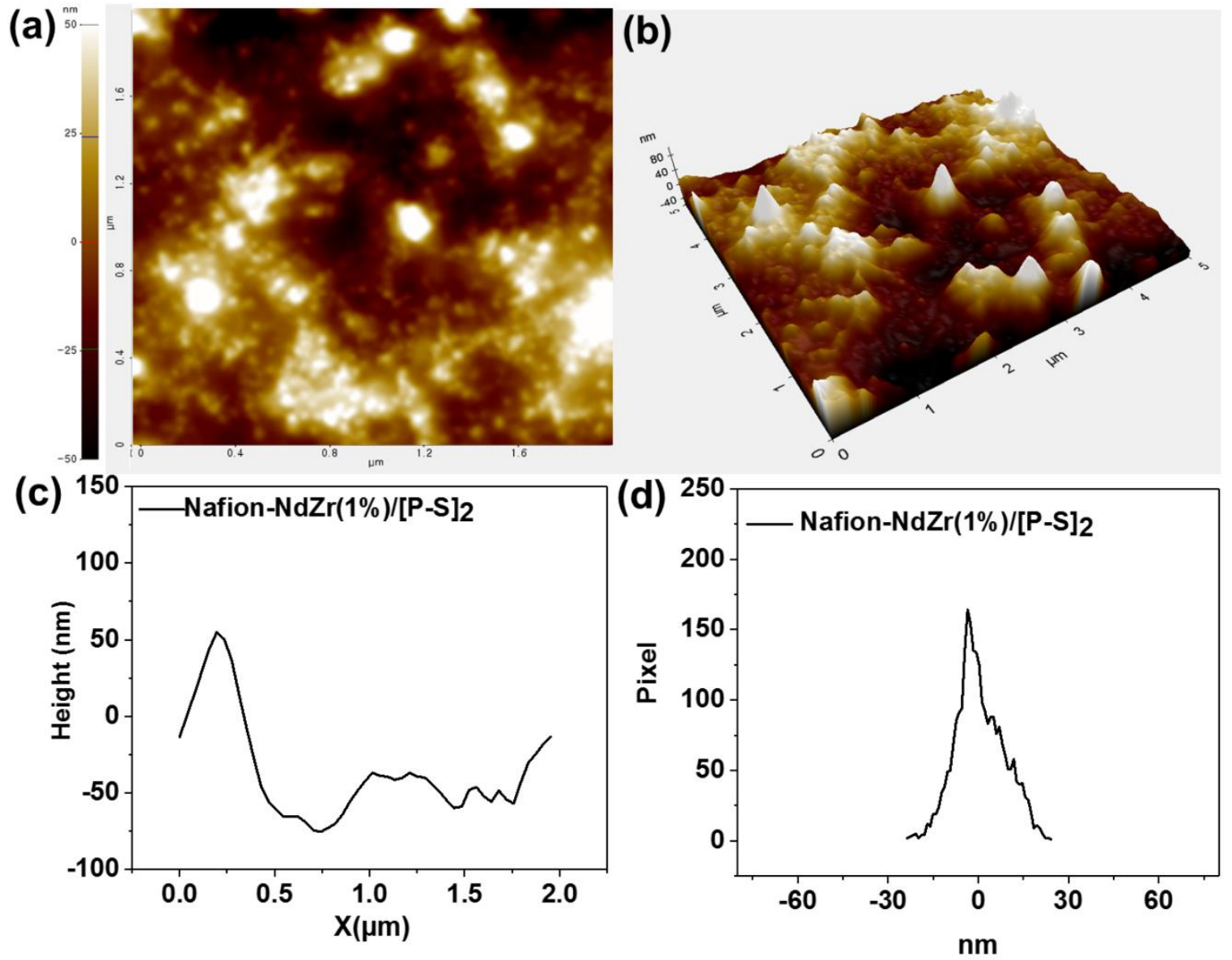

Figure S12. AFM analysis: (a) 2D images, (b) 3D images, (c) Line profile, and (d) Histogram of Nafion-NdZr(1\%)/[P-S $]_{2}$ membrane after 200 charge-discharge VFB cycles. 
Table S2 The performance of VFB operated with Nafion-NdZr(1\%) and Nafion-NdZr(1\%)/[P$\mathrm{S}]_{2}$ membranes in comparison with previous work.

\begin{tabular}{|c|c|c|c|c|c|c|c|}
\hline Membrane & $\begin{array}{c}\text { Thickness } \\
(\mu \mathrm{m})\end{array}$ & $\begin{array}{c}\text { Proton } \\
\text { conductivity } \\
\left.(\mathrm{mS} \mathrm{cm})^{-1}\right)\end{array}$ & $\begin{array}{l}\text { Vanadium } \\
\text { permeability } \\
\left(\mathrm{cm}^{2} \mathrm{~min}^{-1}\right)\end{array}$ & $\begin{array}{c}\text { Coulombic } \\
\text { efficiency } \\
(\%)\end{array}$ & $\begin{array}{c}\text { Current } \\
\text { density } \\
(\mathrm{mA} \\
\left.\mathrm{cm}^{-2}\right)\end{array}$ & $\begin{array}{l}\text { OCV } \\
\text { (h) }\end{array}$ & Ref. \\
\hline Nafion-NdZr(1\%)/[P-S $]_{2}$ & 27.4 & 73.7 & $0.0010 \times 10^{-7}$ & 99.3 & 40 & 513.7 & $\begin{array}{l}\text { This } \\
\text { work }\end{array}$ \\
\hline Nafion-NdZr(1\%) & 22.3 & 78.9 & $0.0027 \times 10^{-7}$ & 97.8 & 40 & 293.2 & $\begin{array}{l}\text { This } \\
\text { work }\end{array}$ \\
\hline SPAEK/PW-mGO(1\%) & 50 & 71 & $0.28 \times 10^{-7}$ & 98.7 & 40 & 458 & S1 \\
\hline $\mathrm{SPAEK} / \mathrm{Ce}_{2} \mathrm{Zr}_{2} \mathrm{O}_{7}(2 \%)$ & 45 & 87 & $0.012 \times 10^{-7}$ & 99.4 & 40 & 441 & S3 \\
\hline SPAEK & 45 & 67 & $0.156 \times 10^{-7}$ & 97.7 & 40 & 172 & S3 \\
\hline SPES/PVA & 170 & 76 & $2.80 \times 10^{-7}$ & 92.6 & 36 & 158 & S4 \\
\hline $\begin{array}{l}\text { Nafion- } \\
\text { (NKFs@NSP/PWA) }\end{array}$ & 120 & 79 & $6.27 \times 10^{-7}$ & 83.5 & 40 & 71 & S5 \\
\hline PTFE/SPEEK/PDDA/PSS & 30 & N/A & $1.87 \times 10^{-7}$ & 96 & 80 & 84 & S6 \\
\hline SPFEK-[PDDA/PSS $]_{2}$ & 130 & 23.8 & $1.16 \times 10^{-7}$ & 82.1 & 30 & 80 & S7 \\
\hline SPEEK/MCM & 75 & 20.72 & $0.16 \times 10^{-7}$ & 99 & 120 & N/A & S8 \\
\hline SPEEK/PAN/-20 & 55 & 15.0 & $11.3 \times 10^{-7}$ & 96.2 & 80 & 62 & S9 \\
\hline SPEEK & 50 & 52.0 & $3.5 \times 10^{-7}$ & 96.1 & 40 & N/A & S10 \\
\hline NRE-212 & 51 & 56 & $3.3 \times 10^{-7}$ & 90 & 60 & 53 & S11 \\
\hline Nafion-[PDDA-PSS $]_{5}$ & NA & 50.3 & $2.85 \times 10^{-7}$ & 95.3 & 40 & 47 & $\mathrm{~S} 12$ \\
\hline Nafion- $[\mathrm{CS}-\mathrm{PWA}]_{3}$ & NA & 51 & $\begin{array}{l}3 \times 10-10 \\
\left(\mathrm{~cm}^{2} \mathrm{~h}^{-1}\right)\end{array}$ & 74.1 & 40 & 70 & S13 \\
\hline Nafion-115 & 125 & 100 & $0.045 \mathrm{Mol} \mathrm{L}^{-1}$ & 88 & 40 & 22 & S14 \\
\hline Nafion-211 & 30 & 31.1 & $1.38 \times 10^{-6}$ & 84.1 & 100 & NA & S15 \\
\hline
\end{tabular}




\section{REFERENCES}

(S1) Aziz, M. A.; Oh, K.; Shanmugam, S. A sulfonated poly (arylene ether ketone)/polyoxometalate-graphene oxide composite: a highly ion selective membrane for all vanadium redox flow batteries. Chem. Commun. 2017, 53, 917-920.

(S2 Kim, J.; Lee, Y.; Jeon, J.-D.; Kwak S.-Y. Ion-exchange composite membranes pore-filled with sulfonated poly(ether ether ketone) and Engelhard titanosilicate-10 for improved performance of vanadium redox flow batteries. J. Power Sources 2018, 383, 1-9.

(S3) Hossain, S. I.; Aziz, M. A.; Han, D.; Selvam, P.; Shanmugam, S. Fabrication of SPAEK-cerium zirconium oxide nanotube composite membrane with outstanding performance and durability for vanadium redox flow batteries. J. Mater. Chem. A 2018, 6, 20205.

(S4) Xie, J.; Li, G.; Tan, W. Preparation and characterization of SPES/PVA (double-layer) membrane for vanadium redox flow battery. High Performance Polymers 2019, 31, 148-153.

(S5) Yang, X.-B.; Zhao, L.; Goh, K.; Sui, X-L.; Meng, L-H.; Wang, Z-B. A highly proton/vanadium-selective perfluorosulfonic acid membrane for vanadium redox flow batteries. New $\mathrm{J}$. Chem. 2019, 43, 11374-11381.

(S6) Teng, X.; Yu, C.; Wu, X.; Dong, Y.; Gao, P.; Hu, H.; Zhu Y.; Dai, J. PTFE/SPEEK/PDDA/PSS composite membrane for vanadium redox flow battery application. $J$. Mater. Sci. 2018, 53, 5204-5215.

(S7) Wang, Y.; Wang, S.; Xiao, M; Han, D; Hickner, M.A.; Meng, Y. Layer-by-layer selfassembly of PDDA/PSS-SPFEK composite membrane with low vanadium permeability for vanadium redox flow battery. $R S C A d v$. 2013, 3, 15467-15474.

(S8) Zeng, L.; Ye, J.; Zhang, J.; Liu, J.; Jia, C. A promising SPEEK/MCM composite membrane for highly efficient vanadium redox flow battery. Sur. and Coa. Tech. 2019, 358, $167-172$.

(S9) Li, Z.; Dai, W.; Yu, L.; Liu L.; Xi, J.; Qiu, X.; Chen, L.; Properties Investigation of Sulfonated Poly(ether ether ketone)/Polyacrylonitrile Acid-Base Blend Membrane for Vanadium Redox Flow Battery Application. ACS Appl. Mater. Interfaces 2014, 6, 18885-18893.

(S10) Jung, H. Y.; Jeong, S.; Kwon, Y. The Effects of Different Thick Sulfonated Poly (Ether Ether Ketone) Membranes on Performance of Vanadium Redox Flow Battery. J. Electrochem. Soc. 2016, 163(1), A5090-A5096. 
(S11) Wu, C.; Lu, S.; Wang, H.; Xu, X.; Peng, S.; Tan, Q.; Xiang, Y. A Novel polysulfonepolyvinylpyrrolidone membrane with superior proton-to-vanadium ion selectivity for vanadium redox flow batteries. J. Mater. Chem. A 2016, 4, 1174-1179.

(S12) Xi, J.; Wu, Z.; Teng, X.; Zhao, Y.; Chen, L.; Qiu, X. Self-assembled polyelectrolyte multilayer modified Nafion membrane with suppressed vanadium ion crossover for vanadium redox flow batteries. J. Mater. Chem. 2008, 18, 1232-1238.

(S13) Lu, S.; Wu, C.; Liang, D.; Tan, Q.; Xiang, Y. Layer-by-layer self-Assembly of Nafion[CS-PWA] composite membranes with suppressed vanadium ion crossover for vanadium redox flow battery applications. RSC Adv. 2014, 4, 24831-24837.

(S14) Jiang, B.; Wu, L.; Yu, L.; Qiu, X.; Xi, J. A comparative study of Nafion series membranes for vanadium redox flow batteries. J. Membr. Sci. 2016, 510, 18-26.

(S15) Li, J.; Zhang, Q.; Peng, S.; Zhang, D.; Yan, X.; Wu, X.; Gong, X.; Wang, Q.; He, G. Electrospinning fiberization of carbon nanotube hybrid sulfonated poly (ether ether ketone) ion conductive membranes for a vanadium redox fow battery. J. Membr. Sci. 2019, 583, 93-102. 